\title{
Connective tissue growth factor in hepatocytes is elevated by carbon tetrachloride via STAT3 activation
}

\author{
WENHSU CHEN ${ }^{1}$, YINGXIAO LI ${ }^{2}$, CHAO-TIEN HSU ${ }^{3}$, CHIANG-SHAN NIU ${ }^{4}$, \\ WEN-HUANG PEN ${ }^{5}$, KAI-CHUN CHENG ${ }^{6}$ and HO-SHAN NIU ${ }^{4}$
}

\author{
${ }^{1}$ Department of Internal Medicine, E-Da Hospital, I-Shou University, Kaohsiung 82401, Taiwan, R.O.C.; \\ ${ }^{2}$ Department of Psychosomatic Internal Medicine, Kagoshima University Graduate School of Medical and Dental Sciences, \\ Kagoshima 890-8520, Japan; ${ }^{3}$ Department of Pathology, E-Da Hospital, I-Shou University, Kaohsiung 82401; ${ }^{4}$ Department of \\ Nursing, Tzu Chi University of Science and Technology, Hualien 97005; ${ }^{5}$ Department of Chinese Pharmaceutical \\ Sciences and Chinese Medicine Resources, College of Chinese Medicine, China Medical University, \\ Taichung 40402, Taiwan, R.O.C.; ${ }^{6}$ Pharmacological Department of Herbal Medicine, Kagoshima University \\ Graduate School of Medical and Dental Sciences, Kagoshima 890-8520, Japan
}

Received June 13, 2019; Accepted November 27, 2019

DOI: $10.3892 / \mathrm{mmr} .2020 .10916$

\begin{abstract}
Carbon tetrachloride $\left(\mathrm{CCl}_{4}\right)$ is widely used to induce hepatic fibrosis. Therapeutic agents alleviate hepatic fibrosis by inhibiting signal transducer and activator of transcription 3 (STAT3) activation. To understand the direct effects of $\mathrm{CCl}_{4}$ on STAT3 expression in the liver, the present study incubated cultured hepatocytes expressing connective tissue growth factor (CTGF) with $\mathrm{CCl}_{4}$. Rats exposed to $\mathrm{CCl}_{4}$ for 8 weeks exhibited hepatic fibrosis, which was confirmed through the assessment of plasma biomarkers. Isolated liver samples were used to determine the protein levels of CTGF and STAT3 using western blotting. In addition, STAT3 expression was silenced in $\alpha$ mouse liver 12 (AML-12) cells using small interfering RNA transfection. In addition, a pharmacological inhibitor, stattic, was used to inhibit STAT3 expression. The incubation of AML-12 cells with $\mathrm{CCl}_{4}$ induced a dose-dependent increase in CTGF expression and STAT3 activation. Notably, silymarin, an extract from milk thistle, inhibited these changes in AML-12 cells and the antioxidant tiron produced similar
\end{abstract}

Correspondence to: Professor Ho-Shan Niu, Department of Nursing, Tzu Chi University of Science and Technology, 880 Section 2, Chien-Kuo Road, Hualien 97005, Taiwan, R.O.C.

E-mail: ts00@ems.tcust.edu.tw

Professor Kai-Chun Cheng, Pharmacological Department of Herbal Medicine, Kagoshima University Graduate School of Medical and Dental Sciences, 8-35-1 Sakuragaoka, Kagoshima 890-8520, Japan E-mail: kc-cheng@m3.kufm.kagoshima-u.ac.jp

Abbreviations: AML-12, $\alpha$ mouse liver 12; $\mathrm{CCl}_{4}$, carbon tetrachloride; CTGF, connective tissue growth factor; STAT3, signal transducer and activator of transcription 3

Key words: $\mathrm{CCl}_{4}$, hepatocytes, STAT3, CTGF effects. Silencing of STAT3 reduced the CTGF expression promoted by $\mathrm{CCl}_{4}$ in the hepatocytes. Additionally, similar to tiron, stattic inhibited CTGF expression induced by $\mathrm{CCl}_{4}$. In conclusion, $\mathrm{CCl}_{4}$ may activate STAT3 through oxidative stress to promote CTGF expression, which is one of the main factors contributing to the risk of hepatic fibrosis.

\section{Introduction}

Liver fibrosis and, ultimately, liver cirrhosis are the common end stages of all chronic liver diseases (1). The initiation of fibrogenesis is characterized by a chronic inflammatory condition. The activation of immunocompetent cells (including Kupffer cells), and not virus- or toxin-induced hepatocellular damage, is the main cause of an increase in proinflammatory cytokines, including tumor necrosis factor (TNF)- $\alpha$, interleukin (IL)-6 and IL-12 (2). These mediators and the accumulation of free fatty acids generate highly reactive oxygen species (ROS), which cause oxidative stress and hepatocyte damage, leading to hepatocellular injury (3). The activation of mesenchymal cells, such as hepatic stellate cells (HSCs, or Ito cells), results in the increased synthesis and interstitial deposition of extracellular matrix (ECM) components (4). Following liver injury, HSCs undergo 'activation', which indicates a transition from quiescent vitamin A-rich cells into proliferative, fibrogenic and contractile myofibroblasts ( $\alpha$-smooth muscle actin-expressing) that produce ECM proteins. This pathway has been considered the canonical pathway in the pathogenesis of liver fibrogenesis (4). Hepatocytes are the major targets in liver fibrosis (5). Damaged hepatocytes release ROS as well as fibrogenic mediators, and induce the recruitment of white blood cells by inflammatory cells. Apoptosis of damaged hepatocytes also stimulates fibrogenic processes in the liver (6). Liver cirrhosis, which is the end-stage of liver fibrosis, is associated with high mortality (7).

Fibrogenic mechanisms depend on the interplay of numerous cytokines (8). Platelet-derived growth factor and 
transforming growth factor (TGF)- $\beta$, which is designated as a fibrogenic master cytokine with multiple effects, are profibrogenic growth factors (9). The natural antagonist of TGF- $\beta$ is bone morphogenetic protein (BMP)-7 (10). HSCs respond markedly to TGF- $\beta$. During liver damage, hepatocyte apoptosis and growth control for regeneration are the primary roles of TGF- $\beta$ (11). Connective tissue growth factor (CTGF) mediates fiber and matrix interactions, serves a role in TGF- $\beta$ signaling and suppresses BMP-7 (12). Generally, CTGF acts as a fibrogenic master switch in the genesis of fibroblasts that produce ECM during organ fibrosis (13). An increase in CTGF expression occurs spontaneously in cultured hepatocytes but not in fresh hepatocytes; TGF- $\beta$ treatment enhances CTGF expression (14). Therefore, CTGF has been suggested as a biomarker for hepatic fibrosis (15). Additionally, CTGF is constantly expressed in activated HSCs in liver fibrosis (16).

Carbon tetrachloride $\left(\mathrm{CCl}_{4}\right)$ has been widely used as an experimental tool in the study of certain hepatotoxic effects (17). $\mathrm{CCl}_{4}$ may form the trichloromethyl radical, $\mathrm{CCl}_{3}{ }^{*}$, which reacts with oxygen to form the trichloromethyl peroxyl radical $\left(\mathrm{CCl}_{3} \mathrm{OO}^{*}\right)$, a highly reactive species that causes oxidative stress. $\mathrm{CCl}_{4}$-induced hepatotoxicity occurs in two phases. In the initial phase, $\mathrm{CCl}_{4}$ is metabolized to form trichloromethyl radicals $\left(\mathrm{CCl}_{3}{ }^{*}\right.$ or $\left.\mathrm{CCl}_{3} \mathrm{OO}^{*}\right)$, which cause membrane lipid peroxidation and finally induce cell necrosis (18). In the second phase of $\mathrm{CCl}_{4}$-induced hepatotoxicity, Kupffer cells in the liver are activated and proinflammatory mediators are produced (19). Additionally, $\mathrm{CCl}_{4}$ activates TNF- $\alpha$, nitric oxide and TGF- $\alpha$ and TGF- $\beta$ in hepatocytes; TNF- $\alpha$ promotes apoptosis and TGFs appear to promote fibrosis (20). Overall, $\mathrm{CCl}_{4}$-induced hepatic fibrosis is associated with multiple factors (21); notably, $\mathrm{CCl}_{4}$-induced liver fibrosis is associated with a higher expression of CTGF in rats (22).

Signal transducer and activator of transcription 3 (STAT3) is a transcription factor associated with liver injury, inflammation and regeneration $(23,24)$. IL- 6 has been reported to activate STAT3 in HSCs, and promote HSC survival, proliferation and activation, thereby contributing to liver fibrogenesis (25). In addition, therapeutic agents ameliorate liver fibrosis through STAT3 inhibition in HSCs and STAT3 is considered a promising fibrotic biomarker and/or therapeutic target in liver fibrosis $(26,27)$. In the rat liver, an increase in STAT3 phosphorylation caused by $\mathrm{CCl}_{4}$ has been demonstrated (28). However, the direct effect of $\mathrm{CCl}_{4}$ on STAT3 expression in the liver remains to be elucidated.

The present study focused on changes in the expression levels of CTGF, an established biomarker of hepatic fibrosis (15), and revealed that the changes were associated with STAT3 activation in the livers of rats who received chronic treatment with $\mathrm{CCl}_{4}$. Additionally, $\alpha$ mouse liver 12 (AML-12) cells, which are immortalized hepatocytes, were used to determine the role of oxidative stress in the increase in CTGF expression through $\mathrm{CCl}_{4}$-induced STAT3 activation.

\section{Materials and methods}

Animals. A total of 18 male Sprague-Dawley rats (weight, 250-280 g; age, 8 weeks) were obtained from the National Laboratory Animal Center (Taipei, Taiwan). Rats were fed in a climate-controlled room $\left(23 \pm 1^{\circ} \mathrm{C} ; 55 \pm 5 \%\right.$ humidity) under a 12-h light/dark cycle and were supplied ad libitum with clean water and food. The experimental protocols were approved by the Institutional Animal Ethics Committee (2017-047) of China Medical University. All experimental procedures were performed in strict accordance with the recommendations in the Guide for the Care and Use of Laboratory Animals as well as the guidelines of the Animal Welfare Act (eighth edition; grants.nih.gov/grants/olaw/guide-for-the-care-and-use-of-laboratory-animals.pdf) to avoid all stressful conditions.

Drug-induced liver injury. The rats were randomly divided into the following three groups ( $\mathrm{n}=6 /$ group): i) Normal control ii) vehicle $\left(0.9 \%\right.$ saline) plus $\mathrm{CCl}_{4}$ (Thermo Fisher Scientific, Inc.) treatment; and iii) $200 \mathrm{mg} / \mathrm{kg}$ silymarin (Sigma-Aldrich; Merck $\mathrm{KGaA}$ ) plus $\mathrm{CCl}_{4}$ treatment. Silymarin is a flavonolignan, which is obtained from the plant milk thistle (29). Liver injury was induced in rats by an intraperitoneal injection of $20 \% \mathrm{CCl}_{4}$ (diluted in olive oil) at $2 \mathrm{ml} / \mathrm{kg}$ twice a week (Monday and Thursday) for 8 weeks $(30,31)$. Additionally, the $\mathrm{CCl}_{4}$-treated rats received a daily oral administration of silymarin at the indicated dose, or were administered the same volume of vehicle used to dissolve silymarin daily. The morphological and behavioral changes of the rats were monitored daily. No sudden death of rats was observed during the present study. A total of $4 \mathrm{~h}$ after the last dosing, rats were anesthetized with $2 \%$ isoflurane and were confirmed to be unresponsive to all stimuli. Blood samples were collected from the descending aorta. Subsequently, the animals were sacrificed by inhalation of $\mathrm{CO}_{2}$ at the rate of $3 \mathrm{l} / \mathrm{min}$ with displacement of $30 \%$ of the cage volume per minute. Once the rats were confirmed to be non-responsive to external stimuli and respiration had ceased, the livers were rapidly excised and weighed. All samples were stored at $-80^{\circ} \mathrm{C}$ until extraction.

Identification of liver injury. Blood samples were collected in heparin-containing tubes and were centrifuged at 2,000 $\mathrm{x}$ g for $10 \mathrm{~min}$ at $4^{\circ} \mathrm{C}$ to obtain the plasma. Subsequently, plasma alanine transaminase (ALT) and aspartate aminotransferase (AST) levels were measured using an autoanalyzer and commercially available ALT (cat. no. 700260; Cayman Chemical Company) and AST (cat. no. MAK055; Sigma-Aldrich; Merck KGaA) kits. The plasma albumin concentration was determined using an ELISA kit (cat.no. ab108789; Abcam). The hydroxyproline levels were also determined using an ELISA kit (cat. no. MAK008; Sigma-Aldrich; Merck KGaA). All the aforementioned kits were used according to manufacturer's protocol. Liver homogenates $(10 \%, w / v)$ were prepared by homogenizing the liver tissues isolated from each rat in $150 \mathrm{mM}$ Tris-HCl-buffered saline (Ph 7.2; Sigma-Aldrich; Merck KGaA). The homogenates were used for western blotting and other assays.

Cell culture. A mouse hepatocyte-derived cell line (AML-12) was obtained from the Culture Collection and Research Center of the Food Industry Institute (BCRC No. 60326) and was cultured in a 1:1 mixture of Dulbecco's Modified Eagle Medium (GE Healthcare Life Sciences) and Ham's F12 medium (Thermo Fisher Scientific, Inc.) supplemented with $0.005 \mathrm{mg} / \mathrm{ml}$ insulin, $0.005 \mathrm{mg} / \mathrm{ml}$ transferrin, $5 \mathrm{ng} / \mathrm{ml}$ selenium, $40 \mathrm{ng} / \mathrm{ml}$ dexamethasone, $10 \%$ fetal bovine serum (GE Healthcare Life Sciences), $100 \mathrm{IU} / \mathrm{ml}$ penicillin and 
$100 \mathrm{U} / \mathrm{ml}$ streptomycin (GE Healthcare Life Sciences). All the cells were cultured in a humidified incubator at $37^{\circ} \mathrm{C}$ in an atmosphere containing $5 \% \mathrm{CO}_{2}$. AML-12 cells were pretreated with stattic, tiron (4,5-dihydroxybenzene-1,3-disulfonic acid disodium salt; Sigma-Aldrich; Merck KGaA) or silymarin, for 30 min, prior to incubation with $\mathrm{CCL}_{4}$ (dissolved in DMSO; Sigma-Aldrich; Merck KGaA) for $24 \mathrm{~h}$ at $37^{\circ} \mathrm{C}$. Control cells were treated with $0.1 \%$ DMSO only.

Small interfering RNA (siRNA) transfection. According to a previously reported protocol (32), duplexed RNA oligonucleotides for rat STAT3 were prepared using siGENOME SMARTpool (Thermo Fisher Scientific, Inc.). The AML-12 cells were transfected with 40 pmol STAT3-specific siRNAs (siSTAT3) or scrambled siRNA (Sc) using Lipofectamine ${ }^{\circledR}$ 2000 reagent (Invitrogen; Thermo Fisher Scientific, Inc.) according to the manufacturer's protocol. The transfected cells were incubated at $37^{\circ} \mathrm{C}$ for $48 \mathrm{~h}$ prior to use. Successful transfection was confirmed through western blotting.

Western blotting. Total protein was extracted from rat liver tissues and AML12 cells using RIPA lysis buffer $(25 \mathrm{mM}$ Tris, $150 \mathrm{mM} \mathrm{NaCl}, 0.5 \%$ sodium deoxycholate, $0.1 \%$ SDS, $1 \%$ Triton-X-100, $\mathrm{pH}$ 7.6) supplemented with phosphatase (cat. no. 78420; Thermo Fisher Scientific, Inc.) and protease inhibitors (cat. no. 539131; Sigma-Aldrich; Merck KGaA). The concentration of sample was quantified using a bicinchoninic acid protein assay kit (Thermo Scientific, Inc.). Equal amounts of protein samples $(20 \mu \mathrm{g})$ were resolved by SDS-PAGE gel electrophoresis using $10 \%$ gels. Following electrophoresis, the proteins were transferred to expanded polyvinylidene difluoride membranes (EMD Millipore) and blocked using $5 \%$ bovine serum albumin (Sigma-Aldrich; Merck KGaA) in Tris-buffered saline and $0.1 \%$ Tween 20 (TBST) for $2 \mathrm{~h}$ at room temperature. The membranes were then incubated overnight at $4^{\circ} \mathrm{C}$ with primary antibodies specific to $\beta$-actin $(1: 5,000$; Sigma-Aldrich; Merck KGaA; cat. no. A5441), phosphorylated (p)-STAT3 (1:1,000; cat. no. ab76315), STAT3 (1:1,000; cat. no. ab68153) and CTGF (1:1,000; cat. no. ab6992). The aforementioned primary antibodies were purchased from Abcam. Following incubation, the membranes were washed with TBST and incubated for $1 \mathrm{~h}$ at room temperature with horseradish peroxidase conjugated secondary antibodies (goat anti-rabbit IgG and goat anti-mouse IgG; cat. nos. AP132P and AP124P; 1:5,000; Sigma-Aldrich; Merck KGaA). The blots were developed using a chemiluminescence kit (Thermo Scientific, Inc.) and immunoblot densities were semi-quantified using a CHEMX400 laser densitometer (Avegene Life Science). The optical densities of the bands corresponding to p-STAT3 (88 kDa), STAT3 (92 kDa), CTGF (36 kDa) and $\beta$-actin $(43 \mathrm{kDa})$ were semi-quantified using ImageJ (version 1.46; National Institutes of Health).

Reverse transcription-quantitative ( $R T-q) P C R$. Total RNA was isolated from the prepared liver homogenates and AML-12 cells using TRIzol ${ }^{\circledR}$ (Invitrogen; Thermo Fisher Scientific, Inc.), followed by chloroform extraction. The extracted mRNA (2 $\mu \mathrm{g} / \mathrm{sample})$ was reverse-transcribed into cDNA using the Transcriptor First Strand cDNA Synthesis kit (Roche Diagnostics) according to the manufacturer's instructions. The
mRNA expression levels of CTGF and STAT3 were measured through RT-qPCR using Taqman probes (Roche Diagnostics) and specific primers on a LightCycler 480 system (Roche Diagnostics). The qPCR cycling conditions were as follows: Initial denaturation at $95^{\circ} \mathrm{C}$ for $10 \mathrm{~min} ; 30$ cycles at $96^{\circ} \mathrm{C}$ for $10 \mathrm{sec}, 60^{\circ} \mathrm{C}$ for $30 \mathrm{sec}$; and final extension at $72^{\circ} \mathrm{C}$ for $10 \mathrm{~min}$. Signal intensities were normalized to GAPDH. The primers used were: CTGF forward, 5'-CCAACTATGATGCGAGCCAACT-3' and reverse, 5'-TTAGCCCGGTAGGTCTTCACACT-3'; STAT3 forward, 5'-CTGGCACCTTGGATTGAGAG-3' and reverse, 5'-CAACGTGGCATGTGACTCTT-3'; and GAPDH forward, 5'-GACATGCCGCCTGGAGAAAC-3' and reverse, 5'-AGC CCAGGATGCCCTTTAGT-3'. Gene expression was quantified using the $2^{-\Delta \Delta \mathrm{Cq}}$ method (33) and normalized to $\beta$-actin.

Statistical analysis. The results are presented as the mean \pm standard deviation from the sample number of each group. Each experiment was performed at least three times. For multiple group comparison, data were statistically analyzed using one-way analysis of variance followed by Tukey's multiple comparison test. The non-parametric Mann-Whitney U test was performed for two-group comparisons. The results were analyzed using SPSS software (version 17; SPSS, Inc.). P<0.05 was considered to indicate a statistically significant difference.

\section{Results}

Silymarin alleviates hepatic fibrosis induced by $\mathrm{CCl}_{4}$ in rats. Consistent with a previous report (34), the rats exposed to $\mathrm{CCl}_{4}$ for 8 weeks presented marked changes in the levels of hepatic fibrosis biomarkers, including plasma AST, ALT, hydroxyproline and albumin levels, compared with vehicle-treated normal rats (Fig. 1). Consistent with a previous study (35), oral administration of silymarin $(200 \mathrm{mg} / \mathrm{kg})$ significantly attenuated high plasma AST and ALT levels in the $\mathrm{CCl}_{4}$-treated rats. However, silymarin alone did not modify AST or ALT levels in the vehicle-treated normal rats. Similar results were observed with other biomarkers, namely hydroxyproline and albumin (Fig. 1). Hydroxyproline is a major component of collagen and changes in hydroxyproline levels are widely used to quantify collagen content. Additionally, albumin is synthesized by the liver and lower-than-normal levels of plasma albumin indicate liver injury (36). The plasma albumin levels were decreased in $\mathrm{CCl}_{4}$-treated rats and this decrease was markedly reversed by silymarin (Fig. 1). Thus, hepatic fibrosis was identified in the rats chronically exposed to $\mathrm{CCl}_{4}$ for 8 weeks.

Changes in fibrotic gene expression during hepatic fibrosis. Western blotting revealed changes in protein levels of p-STAT3 and STAT3. Administration of the effective dose of silymarin to alleviate hepatic fibrosis reversed the increase in p-STAT3/STAT3 (Fig. 2A). Changes in protein levels of CTGF were similar to the changes in p-STAT3/STAT3 levels (Fig. 2B). Notably, activation of STAT3 (p-STAT3/STAT3) was observed in the livers with fibrosis. Silymarin inhibited STAT3 activation and thus, CTGF expression, which alleviated hepatic fibrosis.

Effects of $\mathrm{CCl}_{4}$ on hepatocytes in vitro. The direct effect of $\mathrm{CCl}_{4}$ on hepatocytes was investigated using the cultured AML-12 cell line. Incubation of AML-12 cells with $\mathrm{CCl}_{4}$ 
A

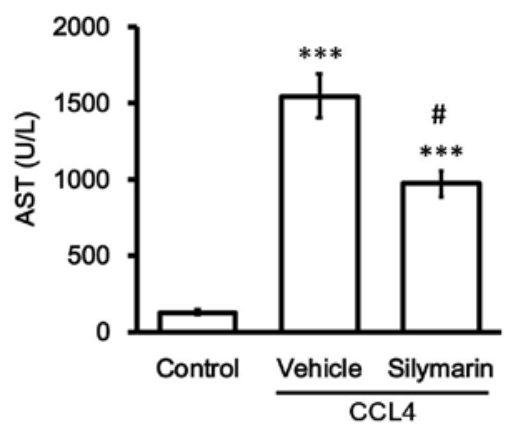

C

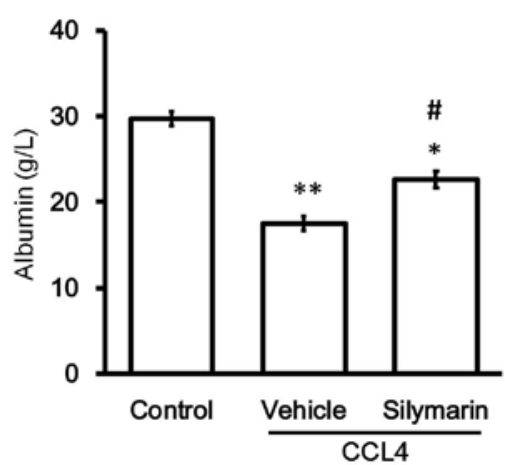

B

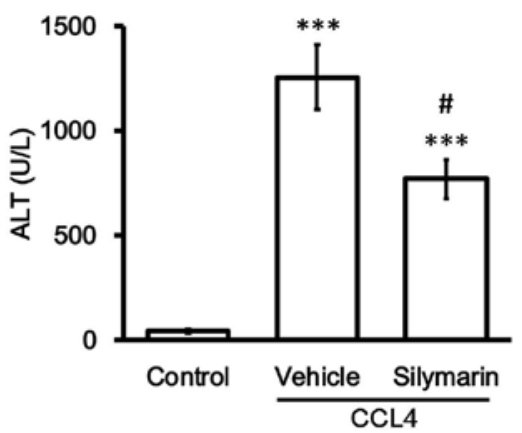

D

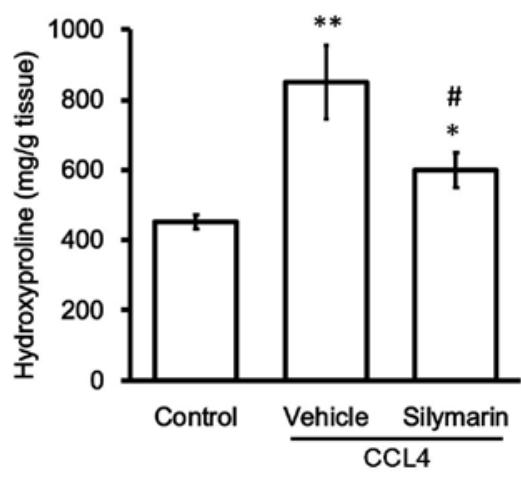

Figure 1. Changes in plasma levels of biomarkers in $\mathrm{CCl}_{4}$-treated rats. Hepatic injury was induced in rats by intraperitoneally injecting $20 \% \mathrm{CCl}_{4}$ at a dose of $2 \mathrm{ml} / \mathrm{kg}$ twice a week for 8 weeks. Plasma biomarkers for hepatic fibrosis, including (A) AST, (B) ALT, (C) albumin and (D) hydroxyproline, were used to compare the three groups of rats: Normal control (control), vehicle plus $\mathrm{CCl}_{4}$ treatment and $200 \mathrm{mg} / \mathrm{kg}$ silymarin plus $\mathrm{CCl}{ }_{4}{ }^{*} \mathrm{P}<0.05,{ }^{* *} \mathrm{P}<0.01,{ }^{* * *} \mathrm{P}<0.001$ vs. the normal control group; ${ }^{\#} \mathrm{P}<0.05$ vs. the vehicle plus $\mathrm{CCl}_{4}$ group. ALT, alanine transaminase; AST, aspartate aminotransferase; $\mathrm{CCl}_{4}$, carbon tetrachloride.

A
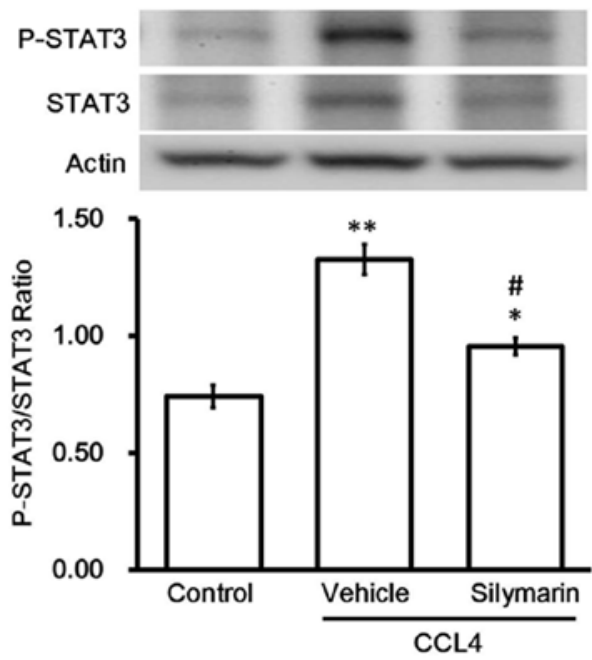

B

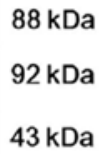

CTGF Actin $6 \mathrm{kDa}$ $43 \mathrm{kDa}$

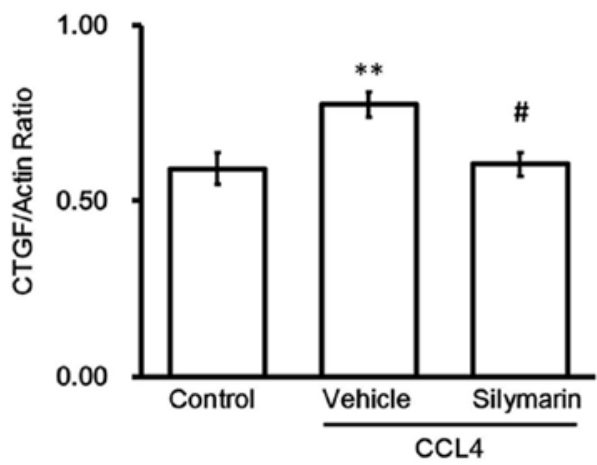

Figure 2. Protein levels of (A) STAT3 or p-STAT3, and (B) CTGF in the liver were determined through western blotting for comparing the three groups of rats: Normal control, vehicle plus $\mathrm{CCl} 4$ and $200 \mathrm{mg} / \mathrm{kg}$ silymarin plus $\mathrm{CCl}_{4} \cdot{ }^{*} \mathrm{P}<0.05,{ }^{* *} \mathrm{P}<0.01$ vs. normal control group; ${ }^{*} \mathrm{P}<0.05$ vs. vehicle plus $\mathrm{CCl}{ }_{4}$ group. $\mathrm{CCl}_{4}$, carbon tetrachloride; CTGF, connective tissue growth factor; p, phosphorylated; STAT3, signal transducer and activator of transcription.

resulted in increased expression of CTGF mRNA and protein. The protein (Fig. 3A) and mRNA (Fig. 3B) expression levels of CTGF were increased after $\mathrm{CCl}_{4}$ treatment in a dose-dependent manner. Additionally, administration of the same dose of $\mathrm{CCl}_{4}$ enhanced the mRNA expression of STAT3 in the AML-12 cells (Fig. 3C). Observation of the liver tissues revealed that $\mathrm{CCl}_{4}$ was directly toxic to hepatocytes; however, $\mathrm{CCl}_{4}$ at $20 \mathrm{mM}$ did not induce damage in the AML-12 cells, which was verified by the results of MTT assay and lactate dehydrogenase measurements (data not shown). 
A
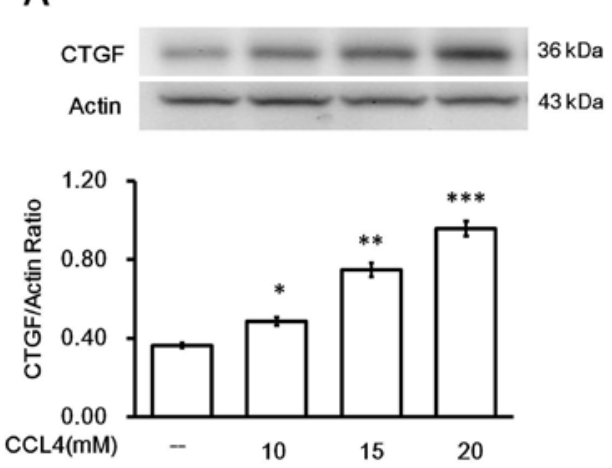

C

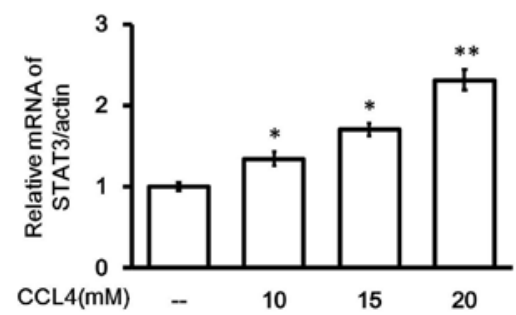

B

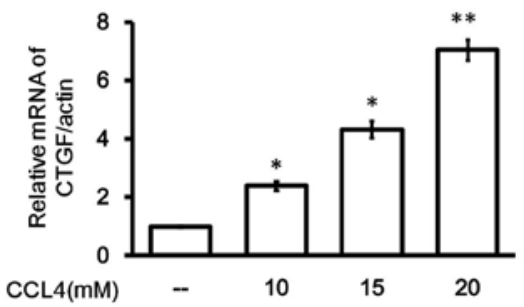

Figure 3. Direct effects of $\mathrm{CCl}_{4}$ on CTGF gene expression and STAT3 activation in cultured hepatocytes (AML-12 cells). The cells were incubated with CCl ${ }_{4}$ at the indicated dose for $24 \mathrm{~h}$ and were compared with those treated with the vehicle (0.1\% DMSO). Differences between the control and $\mathrm{CCl}_{4}$-treated cells are displayed in terms of (A) protein levels of CTGF, (B) mRNA levels of CTGF and (C) mRNA levels of STAT3. ${ }^{*} \mathrm{P}<0.05,{ }^{* *} \mathrm{P}<0.01$ and ${ }^{* * * *} \mathrm{P}<0.001$ vs. the control group. $\mathrm{CCl}_{4}$, carbon tetrachloride; CTGF, connective tissue growth factor; STAT3, signal transducer and activator of transcription 3.

A
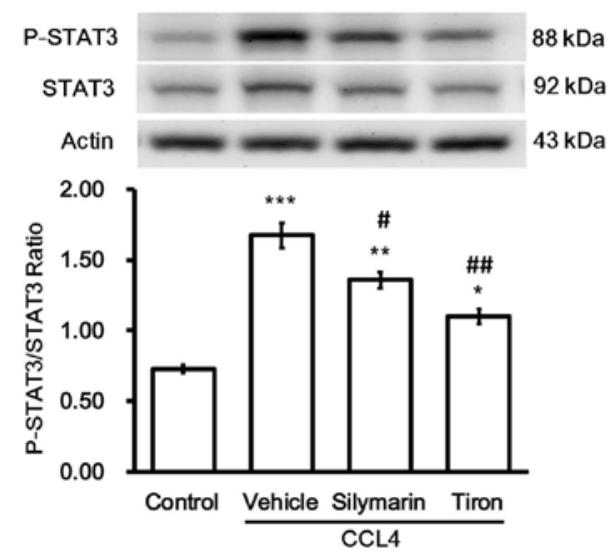

C

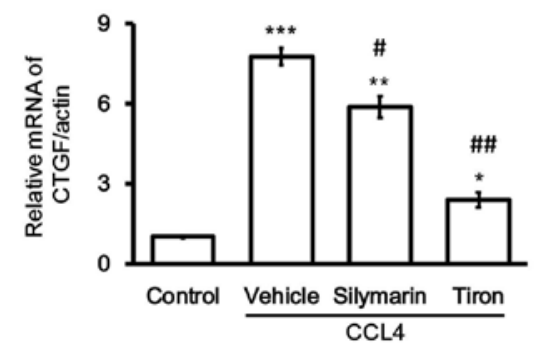

B
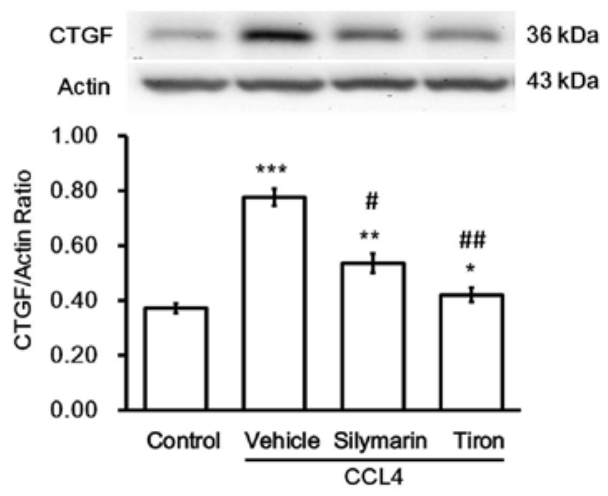

Figure 4. Effects of silymarin and the antioxidant tiron on $\mathrm{CCl}_{4}$ toxicity in cultured hepatocytes (AML-12 cells). AML-12 cells were treated with silymarin or the antioxidant tiron for $30 \mathrm{~min}$ prior to incubation with $\mathrm{CCl}_{4}$. (A) Changes in protein levels of STAT3. (B) Changes in protein levels of CTGF. (C) Changes in mRNA levels of CTGF. ${ }^{*} \mathrm{P}<0.05,{ }^{* *} \mathrm{P}<0.01$ and ${ }^{* * *} \mathrm{P}<0.001$ vs. the normal control group. ${ }^{\#} \mathrm{P}<0.05,{ }^{\# \prime} \mathrm{P}<0.01$ vs. the vehicle plus $\mathrm{CCl}_{4}$ group. $\mathrm{CCl}_{4}$, carbon tetrachloride; CTGF, connective tissue growth factor; p, phosphorylated; STAT, signal transducer and activator of transcription. 
A

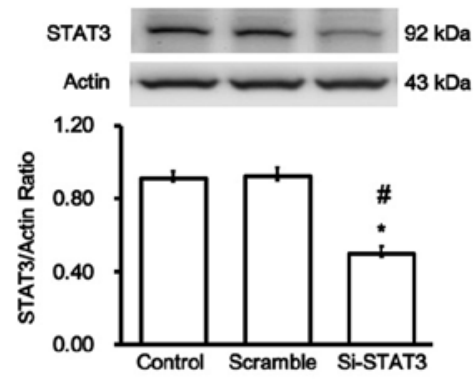

C
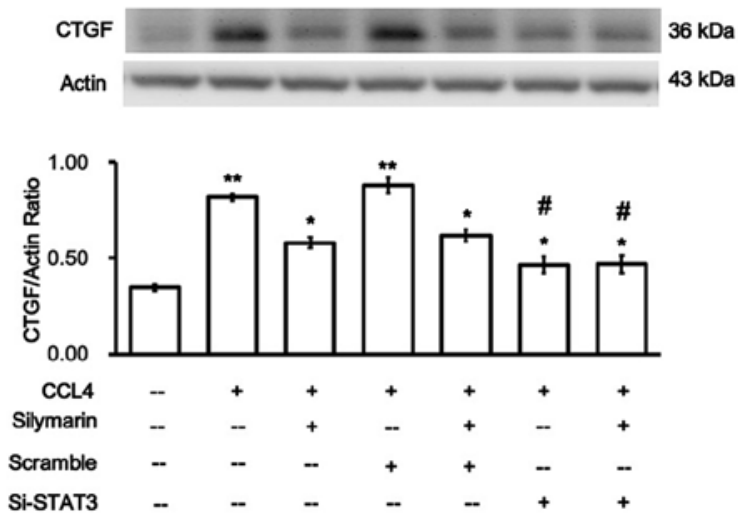

B

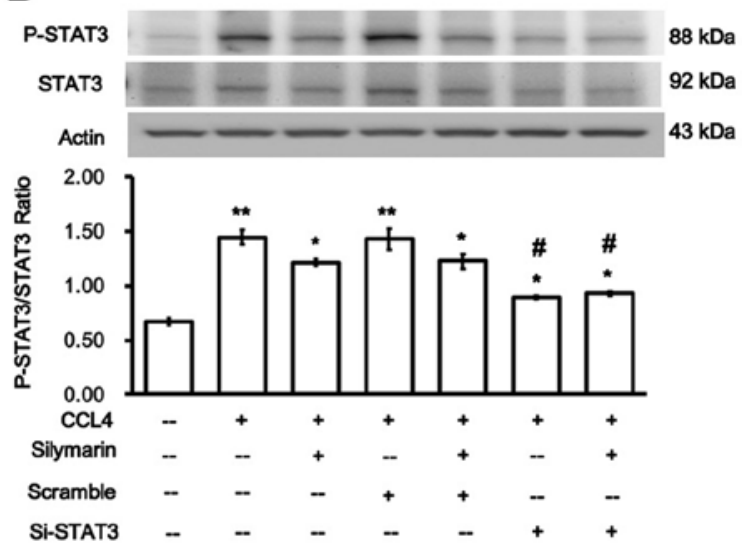

D

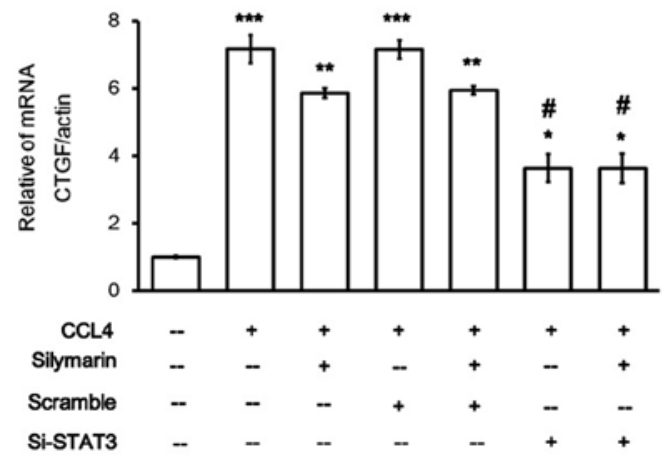

Figure 5. Effect of silencing of STAT3 on CTGF expression in cultured hepatocytes. (A) STAT3 expression was silenced by siSTAT3 transfection in AML-12 cells compared with in the negative control group (transfected with Sc). (B) Changes in p-STAT3 and STAT3 expression after silencing STAT3 in the AML-12 cells; the representative western blotting data are presented in the upper panel and the lower panel indicates the semi-quantified differences in activated STAT3 (p-STAT3/STAT3) among the groups. Changes in CTGF (C) protein levels and (D) mRNA levels after silencing STAT3 in AML-12 cells. (C) Representative blots of CTGF are presented in the upper panel and the lower panel indicates the semi-quantified differences in CTGF expression among the groups. "P<0.05, ${ }^{* *} \mathrm{P}<0.01,{ }^{* * *} \mathrm{P}<0.001$ vs. the normal control group. ${ }^{*} \mathrm{P}<0.05$ vs. the scramble plus $\mathrm{CCl}_{4}$ group. $\mathrm{CCl}_{4}$, carbon tetrachloride; $\mathrm{CTGF}$, connective tissue growth factor; Sc, scrambled; si, small interfering RNA; p, phosphorylated; STAT3, signal transducer and activator of transcription 3.

Effects of antioxidants on the toxicity of $\mathrm{CCl}_{4}$ in hepatocytes. The direct effects of $\mathrm{CCl}_{4}$ on the liver were reproduced in hepatocytes, namely the increase in STAT3 activation (Fig. 4A) and CTGF expression (Fig. 4B). Silymarin inhibited the effects of $\mathrm{CCl}_{4}$ on hepatocytes (Fig. 4). Additionally, another antioxidant, tiron (37), produced an effect similar to that of silymarin.

Role of STAT3 in the increase in CTGF expression induced by $\mathrm{CCl}_{4}$ in hepatocytes. Whether the increase in CTGF expression by $\mathrm{CCl}_{4}$ was mediated by STAT3 was investigated. Firstly, siRNA was used to silence STAT3 expression; silencing was subsequently confirmed (Fig. 5A). Changes in the cells transfected with siSTAT3 were evaluated through comparison with cells transfected with Sc (negative control transfection). However, the expression levels of STAT3 in the cells transfected with Sc did not differ from those in the normal hepatocytes.

p-STAT3/STAT3 expression levels were significantly decreased in the cells transfected with siSTAT3 and treated with $\mathrm{CCL}_{4}$ (Fig. 5B). Notably, CTGF protein (Fig. 5C) and mRNA (Fig. 5D) expression levels were significantly reduced in the
$\mathrm{CCl}_{4}+$ siSTAT3 group. These findings suggested that the attenuation of $\mathrm{CCl}_{4}$-induced liver injury by silymarin occurs via suppression of STAT3 signaling.

Effects of STAT3 inhibitor on CTGF expression in $\mathrm{CCl}_{4}$-treated hepatocytes. According to a previously reported protocol (38), stattic, a pharmacological inhibitor of STAT3, was used. In the presence of stattic, the expression levels of p-STAT3/STAT3 were markedly decreased (Fig. 6A). Similarly, expression levels of CTGF protein (Fig. 6B) and mRNA (Fig. 6C) were significantly attenuated compared with the $\mathrm{CCl}_{4}$ group. This provided additional data to support the hypothesis that the decrease in STAT3 activation results in the reduction of CTGF expression in the hepatocytes.

\section{Discussion}

The results of the present study indicated that $\mathrm{CCl}_{4}$ may activate STAT3 to promote CTGF expression in hepatocytes. $\mathrm{CCl}_{4}$-induced hepatic fibrosis was simulated in rats using previously described methods $(28,30,31)$. A marked increase in the 
A
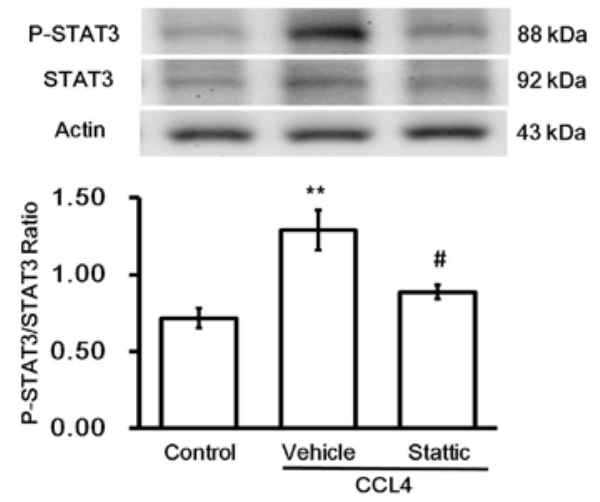

C

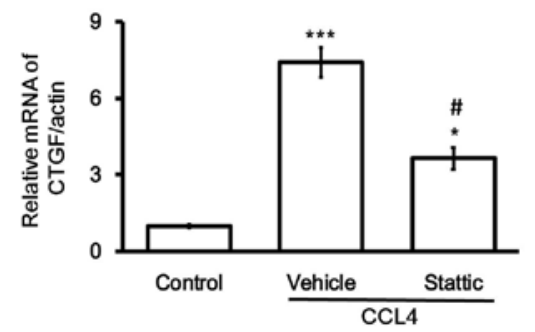

B

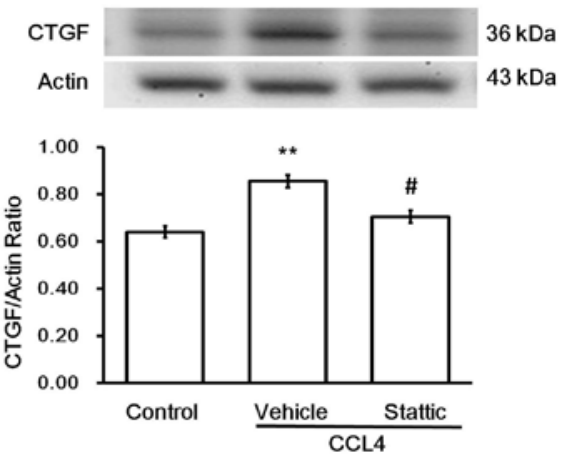

Figure 6. Effect of STAT3 pharmacological blockade on CTGF expression in AML-12 cells. Stattic was used to inhibit STAT3 prior to incubation of cells with $\mathrm{CCl}_{4}$. (A) Confirmation of STAT3 inhibition by stattic in cultured hepatocytes; the representative western blotting data are presented in the upper panel and the lower panel indicates the semi-quantified differences in activated STAT3 (p-STAT3/STAT3) among the groups. A small increase in STAT3 activation was observed in the stattic-treated group compared with the vehicle-treated group. Stattic reduced the $\mathrm{CTGF}(\mathrm{B})$ protein levels and $(\mathrm{C}) \mathrm{mRNA}$ levels. ${ }^{*} \mathrm{P}<0.05$, ${ }^{* *} \mathrm{P}<0.01,{ }^{* * *} \mathrm{P}<0.001$ vs. the normal control group. ${ }^{\#} \mathrm{P}<0.05$ vs. the vehicle plus $\mathrm{CCl}_{4}$ group. $\mathrm{CCl}_{4}$, carbon tetrachloride; $\mathrm{CTGF}$, connective tissue growth factor; p, phosphorylated; STAT, signal transducer and activator of transcription.

levels of plasma biomarkers indicated the success of induction of hepatic fibrosis in the rats using $\mathrm{CCl}_{4}$. Silymarin alleviated hepatic fibrosis; this reagent has been widely used as a positive control in studies on antifibrotic agents $(22,39)$. Similar to a previous study (22), $\mathrm{CCl}_{4}$ treatment in rats enhanced the expression of CTGF in the liver, whereas this was reversed by silymarin. STAT3 activation is undoubtedly required for CTGF induction in activated HSCs (40).

CTGF expression and STAT3 activation were enhanced in hepatocytes by direct exposure to $\mathrm{CCl}_{4}$ in a dose-dependent manner. However, $\mathrm{CCl}_{4}$ did not induce damage of the cultured hepatocytes when administered at an effective dose $(20 \mathrm{mM})$. Silymarin attenuated the $\mathrm{CCl}_{4}$-induced increase in CTGF expression and STAT3 activation in the hepatocytes. The toxic effect of $\mathrm{CCl}_{4}$ has been attributed to the production of ROS and free radicals (41). A number of hepatoprotective agents, including silymarin (42) and other natural products (43), have been documented to counteract oxidative stress-mediated tissue damage through their antioxidant ability and/or ability to scavenge free radicals. The present study applied another antioxidant, tiron (44), to confirm the antioxidant activity of silymarin. Tiron is known to inhibit oxidative stress (37). Notably, tiron inhibited the increase in CTGF expression and STAT3 activation in the cultured hepatocytes. An increase in STAT3 phosphorylation via oxidative stress has been established (45). Therefore, these findings indicated that the $\mathrm{CCl}_{4}$-induced increases in CTGF expression and STAT3 activation in the AML-12 cells may be associated with oxidative stress.

In the present study, the association between STAT3 and CTGF expression was investigated in the cultured hepatocytes. Using siSTAT3, the expression of STAT3 in AML-12 cells was silenced. Consequently, the promotion of CTGF expression induced by $\mathrm{CCl}_{4}$ was not observed in the cells transfected with siSTAT3. Silymarin also inhibited $\mathrm{CCl}_{4}$-induced CTGF expression. These findings suggested that $\mathrm{CCl}_{4}$ induced STAT3 activation to enhance CTGF expression in hepatocytes. Stattic, the pharmacological inhibitor of STAT3 (38), effectively inhibited STAT3 activation and expression in AML-12 cells in the present study, which was consistent with a previous study (46). Stattic has also been reported to be effective at reversing the expression of CTGF in type 1-like diabetic rats (47). The specificity of stattic has been challenged $(48,49)$; however, it has been widely used as a specific STAT3 inhibitor in a number of studies $(46,47,50,51)$.

STAT3 is known as a cytoplasmic transcription factor that transmits extracellular signals to the nucleus (52). Cytokine receptor-dependent Janus kinase (JAK)/STAT activation is generally introduced as the main source of STAT3, whereas an intracellular regulation serves a role in activating STAT3 (40). JAK/STAT activation may be the source of STAT3 that was activated by $\mathrm{CCl}_{4}$ in cultured hepatocytes. Activated STAT3 in the nucleus binds to specific DNA promoter sequences to regulate gene expression (53). 
Therefore, $\mathrm{CCl}_{4}$ promotes CTGF expression via STAT3 activation in hepatocytes. The STAT3 inhibitor S3I-201 has been demonstrated to inhibit the development of liver fibrosis (54). Sorafenib is known as a protein kinase inhibitor and is used in the treatment of liver fibrosis (55). Early antifibrotic treatment with sorafenib reduces the levels of hepatic p-STAT3, however, p-STAT3 increases in response to the dynamic regulation of IL-6 signaling in Kupffer cells (56). Therefore, a combination therapy co-targeting the receptor tyrosine kinases and STAT3 pathway constitutes a promising strategy for improving clinical prognosis (54). However, additional evidence is required from future clinical trials. The main limitation of the present study was that the oxidative stress was not measured, and this requires further investigation in future studies. One concern may be considered as a limitation of the present study: Direct assessment of oxidative stress produced by $\mathrm{CCl}_{4}$ in AML-12 cells may strengthen the role of oxidative stress in the activation of STAT3. This will be the subject of future studies.

In conclusion, the results of the present study suggested that $\mathrm{CCl}_{4}$ may activate STAT3 through oxidative stress to promote CTGF expression in hepatocytes. Therefore, it underscores the requirement for the further development of STAT3 inhibitors alone or in combination with an established drug, such as sorafenib, for patients with liver fibrosis.

\section{Acknowledgements}

The authors would like to thank Miss Yang-Lien Yen (Department of Medical Research, Chi-Mei Medical Center, Taiwan) and Mr Yi-Zhi Chen (Department of Medical Research, Chi-Mei Medical Center, Taiwan) for their technical assistance.

\section{Funding}

No funding was received.

\section{Availability of data and materials}

The datasets used and/or analyzed during the current study are available from the corresponding author on reasonable request.

\section{Authors' contributions}

WC and YL were responsible for the conception and design of the current study, analysis, interpretation of the data and drafting of the manuscript. CTH contributed to the analysis and statistical analysis. KCC contributed to the acquisition of molecular data. CSN contributed to the interpretation of data and submission of the manuscript. WHP and HSN designed the study, revised the manuscript and gave final approval of the version to be published.. All authors discussed, revised and approved the manuscript.

\section{Ethics approval and consent to participate}

The experimental protocols were approved by the Institutional Animal Ethics Committee (2017-047) of China Medical University.

\section{Patient consent for publication}

Not applicable.

\section{Competing interests}

The authors declare that they have no competing interests.

\section{References}

1. Pari L and Sankaranarayanan C: Beneficial effects of thymoquinone on hepatic key enzymes in streptozotocin-nicotinamide induced diabetic rats. Life Sci 85: 830-834, 2009.

2. Nguyen-Lefebvre AT and Horuzsko A: Kupffer cell metabolism and function. J Enzymol Metab 1: pii: 101, 2015.

3. Mello T, Zanieri F, Ceni E and Galli A: Oxidative stress in the healthy and wounded hepatocyte: A cellular organelles perspective. Oxid Med Cell Longev 2016: 8327410, 2016.

4. Gressner OA, Weiskirchen R and Gressner AM: Biomarkers of hepatic fibrosis, fibrogenesis and genetic pre-disposition pending between fiction and reality. J Cell Mol Med 11: 1031-1051, 2007.

5. Higuchi $\mathrm{H}$ and Gores GJ: Mechanisms of liver injury: An overview. Curr Mol Med 3: 483-490, 2003.

6. Canbay A, Friedman S and Gores GJ: Apoptosis: The nexus of liver injury and fibrosis. Hepatology 39: 273-278, 2004.

7. Wang $X$ and $\mathrm{Wu} B$ : Critical issues in the diagnosis and treatment of liver cirrhosis. Gastroenterol Rep (Oxf) 7: 227-230, 2019.

8. Pinzani $M$ and Rombouts K: Liver fibrosis: From the bench to clinical targets. Dig Liver Dis 36: 231-242, 2004.

9. Gressner AM, Weiskirchen R, Breitkopf K and Dooley S: Roles of TGF-beta in hepatic fibrosis. Front Biosci 7: d793-d807, 2002.

10. Sugimoto H, Yang C, LeBleu VS, Soubasakos MA, Giraldo M, Zeisberg M and Kalluri R: BMP-7 functions as a novel hormone to facilitate liver regeneration. FASEB J 21: 256-264, 2007.

11. Schuster Nand Krieglstein K: Mechanisms of TGF-beta-mediated apoptosis. Cell Tissue Res 307: 1-14, 2002.

12. Arnott JA, Lambi AG, Mundy C, Hendesi H, Pixley RA, Owen TA, Safadi FF and Popoff SN: The role of connective tissue growth factor $(\mathrm{CTGF} / \mathrm{CCN} 2)$ in skeletogenesis. Crit Rev Eukaryot Gene Expr 21: 43-69, 2011.

13. Abreu JG, Ketpura NI, Reversade B and De Robertis EM: Connective-tissue growth factor (CTGF) modulates cell signalling by BMP and TGF-beta. Nat Cell Biol 4: 599-604, 2002.

14. Gressner OA, Lahme B, Demirci I, Gressner AM and Weiskirchen R: Differential effects of TGF-beta on connective tissue growth factor (CTGF/CCN2) expression in hepatic stellate cells and hepatocytes. J Hepatol 47: 699-710, 2007.

15. Gressner AM, Yagmur E, Lahme B, Gressner O and Stanzel S: Connective tissue growth factor in serum as a new candidate test for assessment of hepatic fibrosis. Clin Chem 52: 1815-1817, 2006.

16. Meindl-Beinker NM and Dooley S: Transforming growth factor-beta and hepatocyte transdifferentiation in liver fibrogenesis. J Gastroenterol Hepatol 23 (Suppl 1): S122-S127, 2008.

17. Williams AT and Burk RF: Carbon tetrachloride hepatotoxicity: An example of free radical-mediated injury. Semin Liver Dis 10: 279-284, 1990.

18. Manibusan MK, Odin M and Eastmond DA: Postulated carbon tetrachloride mode of action: A review. J Environ Sci Health C Environ Carcinog Ecotoxicol Rev 25: 185-209, 2007.

19. Planaguma A, Claria J, Miquel R, López-Parra M, Titos E, Masferrer JL, Arroyo V and Rodés J: The selective cyclooxygenase-2 inhibitor SC-236 reduces liver fibrosis by mechanisms involving non-parenchymal cell apoptosis and PPARgamma activation. FASEB J 19: 1120-1122, 2005.

20. Badr G, Sayed EA, Waly H, Hassan KA, Mahmoud MH and Selamoglu Z: The therapeutic mechanisms of Propolis against $\mathrm{CCl}_{4}$-mediated liver injury by mediating apoptosis of activated hepatic stellate cells and improving the hepatic architecture through PI3K/AKT/mTOR, TGF-beta/Smad2, Bcl2/BAX/P53 and iNOS signaling pathways. Cell Physiol Biochem 53: 301-322, 2019.

21. Dong S, Chen QL, Song YN, Sun Y, Wei B, Li XY, Hu YY, Liu P and Su SB: Mechanisms of $\mathrm{CCl}_{4}$-induced liver fibrosis with combined transcriptomic and proteomic analysis. J Toxicol Sci 41: 561-572, 2016. 
22. Tzeng JI, Chen MF, Chung HH and Cheng JT: Silymarin decreases connective tissue growth factor to improve liver fibrosis in rats treated with carbon tetrachloride. Phytother Res 27: 1023-1028, 2013.

23. Wang H, Lafdil F, Kong X and Gao B: Signal transducer and activator of transcription 3 in liver diseases: A novel therapeutic target. Int J Biol Sci 7: 536-550, 2011.

24. Gao B, Wang H, Lafdil F and Feng D: STAT proteins-key regulators of anti-viral responses, inflammation, and tumorigenesis in the liver. J Hepatol 57: 430-441, 2012.

25. Nieto N: Oxidative-stress and IL-6 mediate the fibrogenic effects of [corrected] Kupffer cells on stellate cells. Hepatology 44 $1487-1501,2006$

26. Su TH, Shiau CW, Jao P, Liu CH, Liu CJ, Tai WT, Jeng YM, Yang HC, Tseng TC, Huang HP, et al: Sorafenib and its derivative SC-1 exhibit antifibrotic effects through signal transducer and activator of transcription 3 inhibition. Proc Natl Acad Sci USA 112: 7243-7248, 2015.

27. Hui J, Gao J, Wang Y, Zhang J, Han Y, Wei L, Liu Xiaochuang and $\mathrm{Wu} \mathrm{J}$ : Panax notoginseng saponins ameliorates experimenta hepatic fibrosis and hepatic stellate cell proliferation by inhibiting the Jak2/ Stat3 pathways. J Tradit Chin Med 36: 217-224, 2016.

28. Qu W, Huang H, Li K and Qin C: Danshensu-mediated protective effect against hepatic fibrosis induced by carbon tetrachloride in rats. Pathol Biol (Paris) 62: 348-353, 2014.

29. Surai PF: Silymarin as a natural antioxidant: An overview of the current evidence and perspectives. Antioxidants (Basel) 4 204-247, 2015

30. Chen X, Ying X, Zhang W, Chen Y, Shi C, Hou Y and Zhang Y: The hepatoprotective effect of fraxetin on carbon tetrachloride induced hepatic fibrosis by antioxidative activities in rats. Int Immunopharmacol 17: 543-547, 2013.

31. Abdel-Moneim AM, Al-Kahtani MA, El-Kersh MA and Al-Omair MA: Free Radical-scavenging, Anti-inflammatory/Anti-Fibrotic and Hepatoprotective Actions of Taurine and silymarin against $\mathrm{CCl}_{4}$ induced rat liver damage. PLoS One 10 : e0144509, 2015

32. Kuo SC, Li Y, Cheng KC, Niu CS, Cheng JT and Niu HS: Increase in renal erythropoietin receptors in diabetic rats is mainly mediated by hyperglycemia associated with the STAT3/GATA-1 signaling pathway. Biomed Pharmacother 96: 1094-1102, 2017.

33. Livak KJ and Schmittgen TD: Analysis of relative gene expression data using real-time quantitative PCR and the 2(-Delta Delta C(T)) method. Methods 25: 402-408, 2001.

34. Wang R, Wang J, Song F, Li S and Yuan Y: Tanshinol ameliorates $\mathrm{CCl}_{4}$-induced liver fibrosis in rats through the regulation of $\mathrm{Nrf} 2 / \mathrm{HO}-1$ and NF- $\kappa \mathrm{B} / \mathrm{I} \kappa \mathrm{B} \alpha$ signaling pathway. Drug Des Devel Ther 12: 1281-1292, 2018

35. Tsai JH, Liu JY, Wu TT, Ho PC, Huang CY, Shyu JC, Hsieh YS Tsai CC and Liu YC: Effects of silymarin on the resolution of liver fibrosis induced by carbon tetrachloride in rats. J Viral Hepat 15: 508-514, 2008

36. Liu Y, Wen PH, Zhang XX, Dai Y and He Q: Breviscapine ameliorates $\mathrm{CCl}_{4}$-induced liver injury in mice through inhibiting inflammatory apoptotic response and ROS generation. Int J Mol Med 42: 755-768, 2018

37. Morgan A, Ibrahim MA, Galal MK, Ogaly HA and AbdElsalam RM: Innovative perception on using Tiron to modulate the hepatotoxicity induced by titanium dioxide nanoparticles in male rats. Biomed Pharmacother 103: 553-561, 2018.

38. Schust J, Sperl B, Hollis A, Mayer TU and Berg T: Stattic: A small-molecule inhibitor of STAT3 activation and dimerization. Chem Biol 13: 1235-1242, 2006

39. El-Lakkany NM, Hammam OA, El-Maadawy WH, Badawy AA, Ain-Shoka AA and Ebeid FA: Anti-inflammatory/anti-fibrotic effects of the hepatoprotective silymarin and the schistosomicide praziquantel against Schistosoma mansoni-induced liver fibrosis. Parasit Vectors 5: 9, 2012.
40. Liu Y, Liu H, Meyer C, Li J, Nadalin S, Königsrainer A, Weng H, Dooley $\mathrm{S}$ and ten Dijke P: Transforming growth factor- $\beta$ (TGF- $\beta$ )-mediated connective tissue growth factor (CTGF) expression in hepatic stellate cells requires Stat 3 signaling activation. J Biol Chem 288: 30708-30719, 2013.

41. Ha HL, Shin HJ, Feitelson MA and Yu DY: Oxidative stress and antioxidants in hepatic pathogenesis. World J Gastroenterol 16: 6035-6043, 2010.

42. Shaker E, Mahmoud H and Mnaa S: Silymarin, the antioxidant component and Silybum marianum extracts prevent liver damage. Food Chem Toxicol 48: 803-806, 2010.

43. Huo HZ, Wang B, Liang YK, Bao YY and Gu Y: Hepatoprotective and antioxidant effects of licorice extract against $\mathrm{CCl}(4)$-induced oxidative damage in rats. Int J Mol Sci 12: 6529-6543, 2011.

44. Han YH and Park WH: Tiron, a ROS scavenger, protects human lung cancer Calu- 6 cells against antimycin A-induced cell death. Oncol Rep 21: 253-261, 2009

45. Chiu YH, Ku PM, Cheng YZ, Li Y, Cheng JT and Niu HS: Phosphorylation of signal transducer and activator of transcription 3 induced by hyperglycemia is different with that induced by lipopolysaccharide or erythropoietin via receptorcoupled signaling in cardiac cells. Mol Med Rep 17: $1311-1320,2018$

46. Pan Y, Zhou F, Zhang R and Claret FX: Stat3 inhibitor Stattic exhibits potent antitumor activity and induces chemo- and radio-sensitivity in nasopharyngeal carcinoma. PLoS One 8: e54565, 2013.

47. Wang CM, Hsu CT, Niu HS, Chang CH, Cheng JT and Shieh JM: Lung damage induced by hyperglycemia in diabetic rats: The role of signal transducer and activator of transcription 3 (STAT3). J Diabetes Complications 30: 1426-1433, 2016.

48. Heidelberger S, Zinzalla G, Antonow D, Essex S, Basu BP, Palmer J, Husby J, Jackson PJ, Rahman KM, Wilderspin AF, et al: Investigation of the protein alkylation sites of the STAT3:STAT3 inhibitor Stattic by mass spectrometry. Bioorg Med Chem Lett 23: 4719-4722, 2013.

49. Szelag M, Sikorski K, Czerwoniec A, Szatkowska K, Wesoly J and Bluyssen HA: In silico simulations of STAT1 and STAT3 inhibitors predict $\mathrm{SH} 2$ domain cross-binding specificity. Eur J Pharmacol 720: 38-48, 2013.

50. Boengler K, Ungefug E, Heusch G and Schulz R: The STAT3 inhibitor stattic impairs cardiomyocyte mitochondrial function through increased reactive oxygen species formation. Curr Pharm Des 19: 6890-6895, 2013.

51. Sanseverino I,Purificato C, Gauzzi MC and Gessani S: Revisiting the specificity of small molecule inhibitors: The example of stattic in dendritic cells. Chem Biol 19: 1213-1216, 2012.

52. Miller AM, Wang H, Bertola A, Park O, Horiguchi N, Ki SH, Yin S, Lafdil F and Gao B: Inflammation-associated interleukin-6/signal transducer and activator of transcription 3 activation ameliorates alcoholic and nonalcoholic fatty liver diseases in interleukin-10-deficient mice. Hepatology 54: 846-856, 2011.

53. Jung JE, Lee HG, Cho IH, Chung DH, Yoon SH, Yang YM, Lee JW, Choi S, Park JW, Ye SK and Chung MH: STAT3 is a potential modulator of HIF-1-mediated VEGF expression in human renal carcinoma cells. FASEB J 19: 1296-1298, 2005.

54. Wang Z, Li J, Xiao W, Long J and Zhang H: The STAT3 inhibitor S3I-201 suppresses fibrogenesis and angiogenesis in liver fibrosis. Lab Invest 98: 1600-1613, 2018.

55. Wang Y, Gao J,Zhang D, Zhang J, Ma J and Jiang H: New insights into the antifibrotic effects of sorafenib on hepatic stellate cells and liver fibrosis. J Hepatol 53: 132-144, 2010.

56. Deng YR, Ma HD, Tsuneyama K, Yang W, Wang YH, Lu FT, Liu CH, Liu P, He XS, Diehl AM, et al: STAT3-mediated attenuation of $\mathrm{CCl}_{4}$-induced mouse liver fibrosis by the protein kinase inhibitor sorafenib. J Autoimmun 46: 25-34, 2013. 